\title{
Plate Heat Exchanger Performance Optimization Using CFD Simulation
}

\author{
M.B. Maina \\ Department of Mechanical Engineering \\ University of Maiduguri, P.M.B 1069, \\ Maiduguri Borno State Nigeria
}

\author{
G.M. Ngala \\ Department of Mechanical Engineering \\ University of Maiduguri, P.M.B 1069, \\ Maiduguri Borno State, Nigeria.
}

\author{
Muhammad Shuwa \\ Department of Mechanical Engineering \\ University of Maiduguri, P.M.B 1069, \\ Maiduguri Borno State, Nigeria
}

\begin{abstract}
Earlier than this study Plate Heat Exchanger (PHE) is not widely used because of their inability to seal large gaskets between each of the plates. This problem has limited their use to small and low pressure applications. Computational Fluid Dynamics (CFD) software Gambit (pre-processor) and Fluent (solver) were used to modify the existing geometry to further improve their performance. The simulation result has clearly shown how the modification of the plate heat exchanger geometry affects its performance to an optimum level.
\end{abstract}

\section{Keywords-CFD, Performance, Geometry, optimum}

\section{INTRODUCTION}

A heat exchanger is a device which is used to transfer thermal energy (enthalpy) between two or more fluids, between a solid surface and a fluid, or between solid particulates and a fluid, at different temperatures and in thermal contact. They are one of the most important and frequently used processes in engineering. The heat exchange mechanism depends on many other variables such as the heat transfer area, temperature difference, flow rates of the fluids, flow pattern, etc. Heat exchangers are key devices used in a wide variety of thermal applications in industries, including petroleum refining and petrochemical processing; in the food industry, for example, for pasteurization of milk; in the generation of steam for production of power and electricity; in air conditioning houses and vehicles; aircraft and space vehicles.[1] They are the workhorses of the entire field of heating, ventilating, air-conditioning and refrigeration. There are several different types of heat exchangers including shelland-tube plate heat exchangers, double pipe heat exchangers and spiral tube heat exchangers. [2]

Several types of plate heat exchangers are available as described by [3], they can be distinguished on the basis of their specific structure and how the plates are attached together; the most common type is gasket plate heat exchanger, in which they consist of a pack of gaskets and corrugated metal plates pressed together with a frame. A gasket that seals around the plate prevents fluid mixing. It can also be used to create flow configurations such as series, parallel, and multi-pass arrangements by closing and opening ports at the four plate corners. The number of plates, their perforation, the type and position of the gaskets and the location of the inlet and outlet connections at the covers characterize the configuration of plate heat exchanger.[3]

The challenge has always been to find the optimum design with maximum thermal efficiency, lower pressure drop and fouling. By using CFD simulation, the performance of plate heat exchanger can be optimized.

\section{DESIGN OF THE PLATE}

The materials used in designing the PHE are contained in the tables 1 and 2:

Table 1: Plate Materials used in PHE

\begin{tabular}{|l|c|}
\hline Material & Thermal conductivity $\left(\mathrm{W} / \mathrm{m}^{2}\right)$ \\
\hline Stainless steel (316) & 16.5 \\
Aluminum & 205 \\
Inconel 600 & 16 \\
Incolay 825 & 12 \\
Hastelloy C-276 & 10.6 \\
Monel 400 & 66 \\
Nickel 200 & 66 \\
9/10 Cupronickel & 52 \\
70/30 Cupronickel & 35 \\
\hline
\end{tabular}

Table 2: Gasket Materials used in PHE

\begin{tabular}{|l|c|l|}
\hline Gasket Material & $\begin{array}{c}\text { Maximum } \\
\text { operating } \\
\text { temperature } \\
\left({ }^{\circ} \mathrm{C}\right)\end{array}$ & \multicolumn{1}{c|}{ Application } \\
\hline $\begin{array}{l}\text { SBR (styrene } \\
\text { butadiene) }\end{array}$ & 70 & $\begin{array}{l}\text { Oxygenated solvent, acids, } \\
\text { alcohols }\end{array}$ \\
Neoprene & 80 & $\begin{array}{l}\text { General-purpose aqueous, } \\
\text { alkalies, acids and oxygenated } \\
\text { solvent }\end{array}$ \\
Nitrile & 70 & $\begin{array}{l}\text { Alcohols, alkalies, acids, } \\
\text { aliphatic hydrocarbon solvents } \\
\text { Dairy, fruit juices, } \\
\text { pharmaceutical and biochemical } \\
\text { applications, oil, gasoline, } \\
\text { animal and vegetable oils, } \\
\text { alkalies. }\end{array}$ \\
Elurinated Rubber \\
propylene rubber
\end{tabular}




\section{PLATE HEAT EXCHANGER PERFORMANCE}

The six most important parameters as given by [4] are:

1. The amount of heat to be transferred (heat load).

2. The inlet and outlet temperatures on the primary and secondary sides

3. The maximum allowable pressure drop on the primary and secondary sides.

4. The maximum operating temperature.

5. The maximum operating pressure.

6 . The flow rate on the primary and secondary sides.

The amount of heat to be transferred is given in eqn 2.0:

$Q=m c_{p}\left(T_{1}-T_{2}\right)---2.0$

Where:

$\mathrm{Q}$ is the heat transfer rate $(\mathrm{W})$, $\mathrm{m}$ is the mass flow rate $(\mathrm{kg} / \mathrm{s})$,

$P=m x c_{p} x d T---2.1$

$P=U * A * L M T D---2.2$

Which are derived from the following equations:

$\begin{aligned} m & =\frac{P}{C_{p} x d T}--2.3 \\ d T & =\frac{P}{m x c_{p}}-----2.4\end{aligned}$

Where;

$P$ is the heat load $(\mathrm{kW})$,

$m$ is the mass flow $(\mathrm{kg} / \mathrm{s})$,

$C_{p}$ is the Specific heat $(\mathrm{KJ} / \mathrm{kg}-\mathrm{K})$ or $(\mathrm{KJ} / \mathrm{kg}-\mathrm{K})$,

$d T$ is the Difference between inlet and outlet temperatures on one side $(\mathrm{K})$,

$\mathrm{U}$ is the total overall heat transfer coefficient $\left(\mathrm{W} / \mathrm{m}^{2}{ }^{0} \mathrm{C}\right)$,

A is the heat transfer area $\left(\mathrm{m}^{2}\right)$,

LMTD is the log mean temperature difference $\left({ }^{0} \mathrm{C}\right)$.

Logarithmic Mean Temperature Difference:

Logarithmic mean temperature difference (LMTD) is the effective driving force in the heat exchanger.

$L M T D=\frac{\Delta T_{1}-\Delta T_{2}}{\ln \frac{\Delta T_{1}}{\Delta T_{2}}}--2.5$

Here

$$
\Delta T_{1}=T_{h 1}-T_{c 2} \& \Delta T_{2}=
$$

$\operatorname{Pr}=\frac{C_{p} \mu}{k}---2.6$

I. Nusselt number:

The Nusselt number is important dimensionless parameters that represent the temperature gradient at a surface where heat transfer by convection is taking place. It is a function of Reynolds number, the Prandlt number, and if the fluid is still at hydrodynamic entrance region, the Nusselt number will also serve as a function of the length of the tube. However, if the flow is fully developed, the Nusselt number becomes constant. [5]
If the value of the Nusselt number is unity, then it is pure conduction. Higher values means that heat transfer is enhance by convection. A large Nusselt number means very efficient convection. For example a cold fluid flows over a hot surface; the first layer of the fluid (which sticks to the surface) gets heat from the surface by pure conduction. It then gives this newly acquired energy to all of the fluid molecules that it comes in contact with as they pass by it (this is convection).[6]

$N u=0.26(R e)^{0.65} \operatorname{Pr}^{0.4}---2.7$

II. The heat transfer coefficient between the fluid and the heat transfer surface is given by:

$h_{p}=\frac{N u(k)}{D_{e}}----2.8$

III. The friction factor is defined by the following equation $\boldsymbol{f}=\frac{\boldsymbol{k}_{p}}{\boldsymbol{R}_{e}^{m}}-------2.9$

IV. Pressure Drop:

Pressure drop $(\Delta p)$ is in direct relationship to the size of the plate heat exchanger. If it is possible to increase the allowable pressure drop, and incidentally accept higher pumping costs, then the heat exchanger will be smaller and less expensive. [7]. Total pressure drop for both sides is the sum of the channel pressure drop and port pressure drop.

$$
\Delta \boldsymbol{P}_{\mathrm{t}}=\Delta \boldsymbol{P}_{\mathrm{c}}+\Delta \boldsymbol{P}_{p}----
$$

The pressure drop of channel is given by;

$$
\Delta P_{C}=4 f \frac{L_{v} N_{p}}{D_{e}} * \frac{G_{c}^{Z}}{2 \rho} \quad----2.9 .2
$$

The pressure drop in port ducts is given by 2.9.3; $\Delta P_{p}=1.4 N_{p} \frac{G_{c}^{L}}{2 \rho}-\cdots----2.9 .3$

Where:

is the friction factor,

$\mathbf{L}_{\mathbf{v}}$ is the vertical distance between centers of ports (m),

$\mathbf{N}_{\mathbf{p}}$ is the number of passes,

$\mathbf{D}_{\mathrm{e}}$ is the channel equivalent diameter $(\mathrm{m})$.

Overall heat transfer coefficient $(\mathbf{U})$

Overall heat transfer coefficient (U) is a measure of the resistance to heat flow, made up of the resistances caused by the plate material, amount of fouling, nature of the fluids and type of exchanger used. Overall heat transfer coefficient is expressed as $\mathrm{W} / \mathrm{m}^{2}{ }^{\circ} \mathrm{C}$ or $\mathrm{kcal} / \mathrm{h}, \mathrm{m}^{2}{ }^{\circ} \mathrm{C}$.

Where:

$$
\frac{1}{U}=\frac{1}{h_{c}}+\frac{1}{h_{h}}+\frac{t}{k} \quad---2.9 .4
$$

$\mathbf{h}_{\mathbf{h}}$ is the heat transfer coefficient between the warm medium and the heat transfer surface $\left(\mathrm{W} / \mathrm{m}^{20} \mathrm{C}\right)$,

$\mathbf{h}_{\mathbf{c}}$ is the heat transfer coefficient between the heat transfer surface and the cold medium $\left(\mathrm{W} / \mathrm{m}^{2{ }^{\circ} \mathrm{C}}\right)$,

$\mathbf{t}$ is the thickness of the heat transfer surface (m), $\mathbf{k}$ is the thermal conductivity $\left(\mathrm{W} / \mathrm{m}^{\square} \mathrm{C}\right)$. 


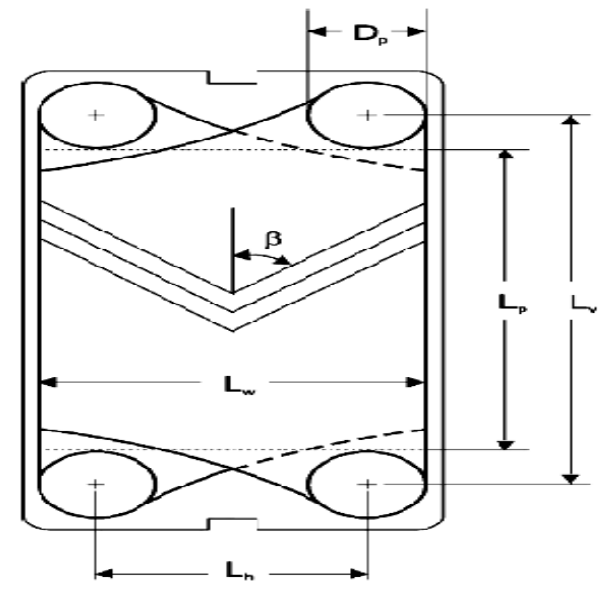

Fig 1; Basic geometry of Plate

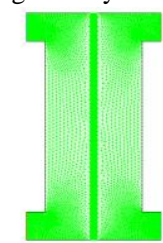

$\operatorname{anc}$

Fig 2: Grids showing three meshed plates carrying hot and cold fluid without mixing the two streams

III. MESHING THE PLATE GEOMETRY USING GAMBIT Table 3: Specifying boundary type's gambit

\begin{tabular}{|c|c|c|}
\hline $\begin{array}{c}\text { EDGES } \\
\text { POSITION }\end{array}$ & NAME & TYPE \\
\hline EDGE 2 & COLD FLUID INLET & $\begin{array}{l}\text { VELOCITY } \\
\text { INLET }\end{array}$ \\
\hline EDGE 20 & COLD FLUID OUTLET & OUTFLOW \\
\hline EDGE 4 & HOT FLUID INLET & \\
\hline EDGE 21 & HOT FLUID OUTLET & INLET \\
\hline $\begin{array}{l}\text { EDGES } 17, \\
18,19\end{array}$ & $\begin{array}{l}\text { WALL 1: WALL AT THE } \\
\text { COOL PLATE }\end{array}$ & OUTFLOW \\
\hline $\begin{array}{l}\text { EDGES 22, } \\
23,24\end{array}$ & $\begin{array}{l}\text { WALL 2: WALL AT THE } \\
\text { HOT PLATE }\end{array}$ & WALL \\
\hline $\begin{array}{l}\text { EDGES 3, } \\
25,27\end{array}$ & $\begin{array}{l}\text { WALL 3: WALL AT THE } \\
\text { OTHER END OF COOL } \\
\text { PLATE }\end{array}$ & $\begin{array}{l}\text { WALL } \\
\text { WALL }\end{array}$ \\
\hline $\begin{array}{l}\text { EDGES } 1, \\
26,28\end{array}$ & $\begin{array}{l}\text { WALL 4: WALL AT } \\
\text { OTHE } \\
\text { PTHER END OF } \\
\text { PLATE }\end{array}$ & WALL \\
\hline $\begin{array}{l}\text { EDGES 26, } \\
27,29,30\end{array}$ & $\begin{array}{l}\text { WALL 5: INTERMEDIATE } \\
\text { WALL }\end{array}$ & WALL \\
\hline
\end{tabular}

Table 4.Specifying continuum boundary types in gambits

\begin{tabular}{|l|l|l|}
\hline FACES & NAME & TYPE \\
POSITION & & \\
\hline FACE 1 & HOT FLUID FLOW & FLUID \\
FACE 3 & COLD FLUID FLOW & FLUID \\
FACE 4 & MIDDLE PLATE & SOLID \\
\hline
\end{tabular}

\section{SETTING THE BOUNDARY CONDITIONS}

Table 5: Boundary condition for the velocity inlet at cold stream

\begin{tabular}{|l|l|}
\hline Velocity specification method & $\begin{array}{l}\text { Magnitude, Normal to } \\
\text { boundary }\end{array}$ \\
\hline Reference frame & Absolute \\
Velocity magnitude & $0.5 \mathrm{~m} / \mathrm{s}$ \\
Specification method & $\mathrm{K}$ and Epsilon \\
Turbulent kinetic energy $\left(\mathrm{m}^{2} / \mathrm{s}^{2}\right)$ & 1 \\
Turbulent dissipation rate $\left(\mathrm{m}^{2} / \mathrm{s}^{3}\right)$ & 1 \\
Temperature & 298 \\
& \\
\hline
\end{tabular}

Table 6: Boundary condition for the velocity inlet for hot stream
\begin{tabular}{|l|l|}
\hline Velocity specification & $\begin{array}{l}\text { Magnitude, Normal to } \\
\text { boundary }\end{array}$ \\
\hline Reference frame & Absolute \\
Velocity magnitude & $0.5 \mathrm{~m} / \mathrm{s}$ \\
Specification method & $\mathrm{K}$ and Epsilon \\
Turbulent kinetic energy & 1 \\
Turbulent dissipation rate & 373 \\
Temperature & \\
\hline
\end{tabular}

Effective area of plate is given by:

$$
A=L * W \quad--------2.6
$$

Where:

$\mathrm{L}$ is the length of the plate

$\mathrm{W}$ is the width of the plate.

Number of plate $=\frac{\text { total heat transfer area }}{\text { effective area }}--2.7$

I. Number of channels is given by:

$$
N_{C}=\frac{N-1}{2}-\cdots----2.8
$$

Where:

$\mathrm{N}$ is the number of plate.

II. The channel cross sectional area is:

$A_{c}=b * W \quad--------2.9$

Where:

$\mathrm{A}_{\mathrm{c}}$ is the channel cross sectional area $\mathrm{b}$ is the plate spacing.

III. Channel equivalent diameter is:

$D_{e}=\mathbf{2} * b \quad-------\mathbf{3 . 0}$

Where: $D_{\mathrm{e}}$ is equivalent diameter 


\section{RESULTS AND DISCUSSION SIMULATION RESULTS}
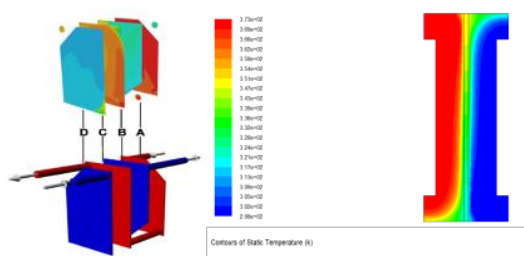

Fig 4: Contours of Static Temperature (K) showing midplane temperature distribution for the channels of a series flow arrangement: 2D model results; Contours of temperature distribution within the plates showing the simulation results at which heat will be transferred from one medium to another, where the minimum temperature for cold stream was $298 \mathrm{k}$ and the maximum temperature was $321 \mathrm{k}$ and for the hot stream minimum temperature was $354 \mathrm{k}$ and the maximum was $373 \mathrm{k}$ respectively.

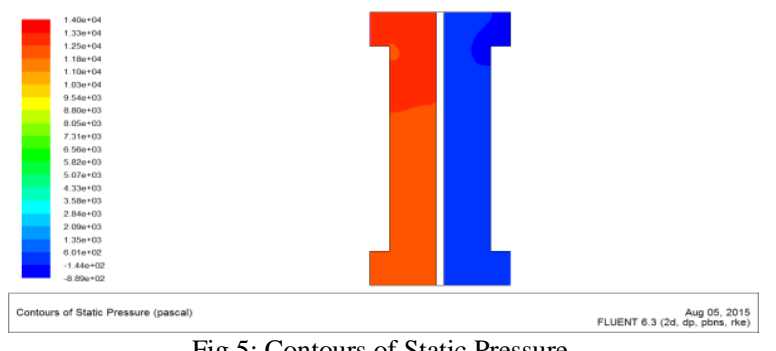

Fig 5: Contours of Static Pressure.

Contours of static pressure showing the simulation results for pressure drop within Midplane for the channels of a series flow arrangement: 2D model results of the plate from inlet to the outlet port, the results shows variation of pressure within the plates, the pressure decreases due to head loss. The pressure of the fluid decreases due to energy losses and the magnitude of velocity near the walls are smaller compared to areas far from the walls due to shear stresses exerted from the wall to the fluid.
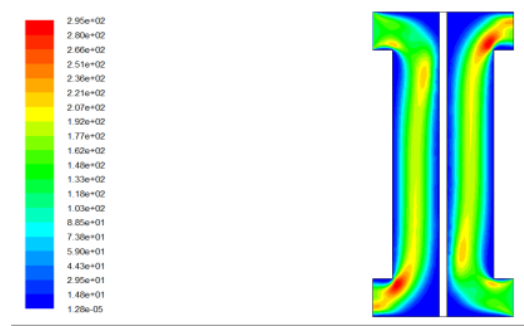

Fig 6: Contours of Dynamic Pressure

Contours of dynamic pressure distribution showing the variation at the entrance of both the hot fluid and cold fluid and the maximum dynamic pressure occurs along the plate at about 295 Pascal while the minimum dynamic pressure is about 128 Pascal

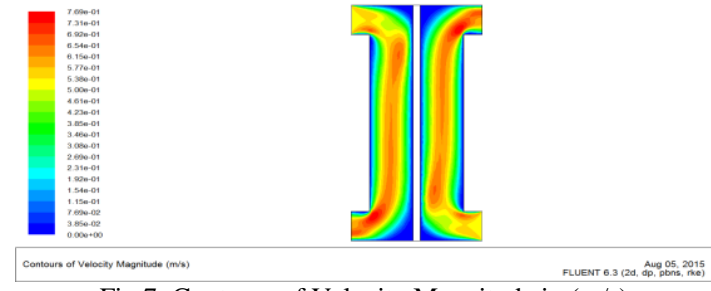

Fig 7: Contours of Velocity Magnitude in (m/s)

Contours of velocity distribution showing the velocity variation at the entrance and within the Midplane for the channels of a series flow arrangement: 2D model results of the plates near the walls showing velocity magnitudes are low due to shear stresses

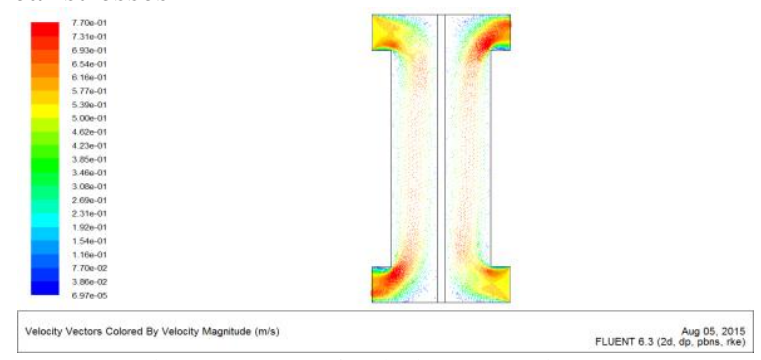

Fig 8: Contours of Velocity Vectors in $(\mathrm{m} / \mathrm{s})$

Contours of velocity vectors distribution showing the velocity variation at the entrance and within the plates, near the walls velocity magnitudes are low in the series arrangement as clearly shown in the figure; this is also similar to the behavior in fig 7 influence by shear stresses.

\section{CONCLUSSION}

Using a CFD tool it was possible to build a virtual prototype of a PHE with four channels and flat plates. The simulation results included outlet temperatures, heat load, as well as the 2D temperature and velocity distribution.

The plate heat exchanger was successfully modeled using Gambit and Fluent. The simulation was carried out by meshing the channels of the plate heat exchanger with counter flow configuration, the simulation setup was performed to study water-to-water heat transfer in the plate heat exchanger, After convergence the results show that the heat rejection rate of water to water in the plate heat exchanger were obtained where the maximum temperature is $373 \mathrm{k}$ and the minimum is $298 \mathrm{k}$, the pressure of the fluid decreases due to energy losses and the magnitude of velocity near the walls is smaller compared to areas far from the walls due to shear stresses exerted from the wall to the fluid. The detailed results from the CFD model allow the analysis of velocity and temperature distribution inside the PHE. High temperature regions and stagnation areas could be observed, indicating regions susceptible to fouling. Examples of temperature and velocity distribution were presented in Figs. 4, 7 and 8 for a series arrangement. Heat transfer of the plate heat exchanger was also studied using CFD software i.e. Gambit and Fluent to produce numerical results. By using CFD method we can design a shape for the plate heat exchanger that has less pressure drop and also we can design a more effective plate that will give high rate of heat transfer, therefore FLUENT software is suitable to analyze the behavior of the flow in a process. 


\section{REFERENCES}

(1) Fernandes, C.S., Dias, R., Nóbrega, J.M., Afonso, I.M., Melo, L.F and Maia, J.M., (2005) Simulation of stirred yoghurt processing in plate heat exchangers, Journal of Food Engineering 69, 281-290

(2) Hamaruddin, Wan Nurmaisarah BT Wan, (2012), Study of Heat Transfer in Plate Heat Exchanger by Using CFD Simulation, publshed BEng Thesis (Gas Technology) UMP.

(3) Flavio C.C. Galeazzoa, RaquelY. Miurab, Jorge A.W. Gutc and Carmen C. Tadini (2006) "Experimental and numerical heat transfer in a plate heat exchanger" Chemical Engineering Science 61, $7133-7138$

(4) Lin J.H., Huang C.Y., Su C.C., (2007) "Dimensional Analysis for the Heat Transfer Characteristics in the Corrugated Channels of Plate Heat Exchangers", International Communications in Heat and Mass Transfer 34, pp.304-312

(5) Morris, F. H., Whitman, W. G., (1928) "Heat Transfer for oil and water in pipes" Industrial and Engineering chemistry, 20, No 3.

(6) www.coolingzone/library, accessed 2017

(7) Warnakulasuriya F.S.K, W.M. Worek (2008); "Heat transfer and pressure drop Properties of high viscous solutions in plate heat exchangers" International Journal of Heat and Mass Transfer 51, PP. 52-67 